\title{
LA POSICIÓN CONSTITUCIONAL DEL PODER JUDICIAL EN BOLIVIA
}

HORACIO ANDALUZ VEGACENTENO 
SUMARIO

I. PODER JUDICIAL Y SEPARACIÓN DE PODERES. II. LEGITIMIDAD DEMOCRÁTICA DE LOS TRIBUNALES. III. INDEPENDENCIA JUDICIAL. IV. DERECHO ORDINARIO. V. EL JUEZ PRECONSTITUIDO POR LEY EN LA JURISPRUDENCIA 


\title{
LA POSICIÓN CONSTITUCIONAL DEL PODER JUDICIAL EN BOLIVIA
}

POR

\author{
HORACIO ANDALUZ VEGACENTENO* \\ Profesor de Derecho \\ Universidad Privada de Santa Cruz de la Sierra
}

\section{PODER JUDICIAL Y SEPARACIÓN DE PODERES}

1. O el poder judicial es independiente o es subordinado. Si es lo primero, es el poder judicial de un Estado de Derecho. Si es lo segundo, no hay Estado de Derecho.

2. Es independiente si está habilitado para hacer inexequibles los actos del poder público. Significa que participa del sistema de frenos y contrapesos. Está posicionado a la par de los poderes ejecutivo y legislativo. En la tradición constitucional anglo-americana, el poder judicial ocupa este lugar por mérito propio. El rule of law (Estado de Derecho) fue una creación histórica de los tribunales ${ }^{1}$.

* Master of Laws (Harvard Law School). Árbitro (Cámara de Industria, Comercio y Turismo de Santa Cruz). Antiguo alumno de la Academia de La Haya de Derecho Internacional. Publicación vinculada a este tema: Aplicación judicial de la constitución (El País/2010).

${ }^{1}$ En su sentido formal al menos, la idea de un Estado de Derecho es de los tribunales ingleses. Su formulación teórica vino dos siglos después, en Alemania, de la mano de Von Mohl (1844) y, entre otros, de Bähr (1864): «el Derecho y la ley sólo pueden adquirir significado y poder real donde encuentran un pronunciamiento judicial dispuesto para su realización» (B̈̈HR, Otto; El Estado de Derecho, 1864, p. 12, cit. por Sommermann, Kart-Peter; El papel de la Ley alemana de la Justicia Administrativa para la realización del Estado de Derecho, en ABERASTURI, Pedro (coordinador); Ley de la Justicia Administrativa Alemana, $1^{a}$ edición, Buenos Aires, Konrad Adenauer/Abeledo Perrot, 2009, p. 4). 
Significaba (1) su vinculación al common law (derecho común) y (2) su independencia de las órdenes del monarca o sus delegados.

Esto arraigaba en las doctrinas inglesas de (1) la supremacía del common law y (2) el debido proceso. Ambas se deben al juez Coke (1552-1634). En la primera puso al common law como fundamento del sistema jurídico británico. La aplicó en el asunto Bonham (1610), que revocó una decisión de naturaleza administrativa con pié en que violaba el principio del common law según el cual ningún hombre debe ser juez de su propia causa ${ }^{2}$. En la segunda hizo equivalentes el debido proceso y la expresión law of the land (ley del país), que venía de la Carta Magna (1215) como una limitación al poder del rey para encarcelar o desposeer a una persona de sus bienes, «a no ser por un juicio legal de sus pares y por la ley del país» (párrafo 39). De aquí concluyó que el debido proceso incluía las garantías procesales contra el ejercicio arbitrario del poder (procedural due process) y la limitación sustantiva del poder gubernamental (substantive due process). La aplicó en el asunto Probibitions (1607), que negó que el rey pudiese juzgar directamente. Sólo podía hacerlo a través de los tribunales, «de acuerdo con el derecho y la costumbre de Inglaterra» ${ }^{3}$ y en el asunto Proclamations (1611), que negó que pudiese crear nuevos delitos: ese era un monopolio del poder legislativo, y lo suyo un acto de usurpación ${ }^{4}$.

Hasta aquí el derecho inglés. Las colonias americanas independizadas (1776) dieron a sus tribunales la misma competencia que tenían sus pares ingleses para (1) imponer a la administración el cumplimiento de un acto debido (writ of mandamus) y (2) cuestionar la legalidad de sus actos (quo warranto). Se trataba de reivindicar el derecho de los colonos de ejercer el mismo grado de libertad del que gozaban los ingleses. El control de constitucionalidad estaba ad portas. Apareció primero como un argumento de parte en las judicaturas estaduales de Rhode Island (Trevett v. Weeden, 1786) $)^{5}$ Carolina del Norte (Bayard v. Singleton, 1787). Luego como un dictum de la Corte Suprema de Justicia (Hylton v. United States,

${ }^{2}$ Cit. por Kelly, Alfred H; Harrison, Winfred A.; Belz, Herman; The American Constitution. Its Origins and Development (Volumen I, $7^{\mathrm{a}}$ edición, Nueva York, W.W. Norton \& Company, 1991), p. 61.

${ }^{3}$ Cit. por García de EnTerría, Eduardo; La lengua de los derechos. La formación del derecho público europeo tras la Revolución Francesa (2 $2^{\mathrm{a}}$ reimpresión, Madrid, Alianza, 2001), p. 148.

${ }^{4}$ Cit. por García Pelayo, Manuel; Derecho constitucional comparado ( $1^{\mathrm{a}}$ edición, Madrid, Alianza, 1999), p. 262.

${ }^{5}$ Cf. Kelly, Alfred H; Harrison, Winfred A.; Belz, Herman; en ob. cit. en nota al pie 2, p. 170.

${ }^{6}$ HaInes, Charles Grove; The American Doctrine of Judicial Supremacy ( $1^{\mathrm{a}}$ edición, Nueva York, Russell \& Russell, 1959), pp. 105-106 y 115-117. 
1796) ${ }^{7}$. Y finalmente fue aplicado en Marbury v. Madison ${ }^{8}$ (1803), cuando William Marbury solicitó a la Corte un mandamus para que el Secretario de Estado le entregase su nombramiento de juez de paz.

3. El poder judicial concebido por la Revolución Francesa no podía contraponerse al ejercicio del poder. Nació histórica e ideológicamente subordinado. (1) Los tribunales estaban identificados con el estamento nobiliario, derrotado en 1789. A pesar de su cuna, en los últimos tiempos del Antiguo Régimen habían enjuiciado los actos de la administración real, oponiéndose. Los revolucionarios no querían que sus actos corriesen la misma suerte. Su enjuiciamiento fue asimilado al prevaricato, prohibiéndoselo. (2) Esta posición venía de una lectura esquemática de la ideología de la división de poderes. Montesquieu aplicaba el sistema de frenos y contrapesos a los poderes legislativo y ejecutivo. Y como el primero lo disgregaba en dos cuerpos (el de nobles y el del pueblo), los dos poderes sumaban tres. A los tribunales correspondía la ejecución de las leyes. Eran el «poder ejecutivo de los que dependen del derecho civil». Quedaban subordinados al poder que les autorizaba a ejecutarlas?.

Esta posición no podía sostenerse. Violaba la Declaración de Derechos del Hombre y del Ciudadano de 1789. Su artículo 7 positivó el principio de legalidad, en sentido lato $^{10}$. Si los poderes públicos sólo podían hacer aquello para lo cual habían sido habilitados, entonces los actos no autorizados eran arbitrarios. La libertad general de actuación nacía del artículo $5^{11}$. Y el artículo 16 asentaba el régimen constitucional en la garantía efectiva de los derechos ${ }^{12}$. Si los actos arbitrarios no podían ser enjuiciados, el principio de legalidad caería por su base. Y con él, la garantía efectiva de la libertad general de actuación de los ciudadanos. De quedarse así, la Revolución habría dado un rodeo para llegar al mismo punto: el enseñoramiento de la administración sobre los ciudadanos. Se instituyó un remedio, pero la cura no fue completa. Siguió asumiendo que los tribunales no podían enjuiciar los actos del poder público. La salida consistió en que la admi-

\footnotetext{
73 U.S. 171 (1796).

85 U.S. (1 Cranch) 137 (1803).

${ }^{9}$ Cf. Montesquieu, Ch.; El espiritu de las leyes (reimpresión, Madrid, Tecnos, 1987), pp. 107 y 113 .

$10 «(\ldots)$. Los que solicitan, facilitan, ejecutan o hacen ejecutar órdenes arbitrarias deben ser castigados; pero todo ciudadano llamado o requerido en virtud de lo establecido en la Ley debe obedecer inmediatamente (...)».

${ }^{11} \ll(\ldots)$. Todo lo que no está prohibido por la Ley no puede ser impedido, y nadie puede ser obligado a hacer lo que la Ley no ordena».

12 «Toda sociedad en la que la garantía de los derechos no está asegurada, ni la separación de poderes establecida, no tiene constitución».
} 
nistración juzgue a la administración, porque, dijeron, «juzgar a la administración es administrar». La Constitución napoleónica del año VIII (1799) creó el Consejo de Estado. Se ocuparía de las reclamaciones patrimoniales contra la administración y del control de legalidad de sus actos (exceso de poder). Pronto tomó características judiciales. Fue la causa moderna de que en el sistema continental las acciones contra la administración estén reservadas a tribunales especializados, distintos a los tribunales civiles.

El control judicial de los actos de la administración se había impuesto en Europa para el siglo XIX. Pero el control de constitucionalidad tardó más en llegar. Como en la tradición continental no se usaba respetar el carácter vinculante de los precedentes, confiar la tarea a la jurisdicción ordinaria ponía en peligro la unidad del sistema jurídico ${ }^{13}$. La creación de un tribunal especializado en la guarda de la constitución se produjo en Austria y Checoslovaquia en 1920, y en España en 1931. Ninguno de ellos resistió la crisis liberal que terminó con la post-guerra. La aplicación judicial de la constitución maduró en los sistemas de cuño romano-germánico recién luego de los ejemplos de la Corte Constitucional italiana (1947) y del Tribunal Constitucional Federal alemán (1949).

4. En la Constitución de Bolivia el poder judicial participa del sistema de frenos y contrapesos. Es titular de (1) la defensa de la Constitución (acciones constitucionales) y (2) del control de las actuaciones administrativas (proceso contencioso-administrativo).

De lo primero pueden rastrearse antecedentes hasta las reformas constitucionales de 1861. Ya aquí la Corte Suprema «[conocía] de los negocios de puro derecho, cuya decisión depend[ía] de la constitucionalidad o inconstitucionalidad de las leyes» (artículo 65.2). Pero la guarda de la Constitución recién fue eficaz en las reformas de 1994, que se la confiaron al Tribunal Constitucional (artículos 119-121). Recién aquí la Constitución rigió como una auténtica norma jurídica. La supremacía de la constitución es una cuestión de hecho. Es la norma fundacional del sistema jurídico en la medida de su efectividad para dotar de validez a la pluralidad de normas que lo integran. Este es el dato fáctico

13 «Aunque los tribunales en Estados Unidos sólo tienen el poder para inaplicar al caso concreto la norma que declaran inconstitucional, el peligro de un práctica contradictoria entre los órganos de aplicación no es aquí ni remotamente tan grave como lo era en Austria antes del establecimiento del Tribunal Constitucional. (...). [Como] las decisiones de la Corte Suprema vinculan a todos los demás tribunales, en tanto los tribunales americanos se consideren obligados por los precedentes de la Corte rechazando la aplicación de una norma a un caso concreto debido a su inconstitucionalidad, la decisión tiene prácticamente los mismos efectos que la anulación general de tal norma» (KELSEN, Hans; Judicial Review of Legislation: A Comparative Study of the Austrian and the American Constitution, 4-2 The Journal of Politics, 1942, pp. 188-189). 
de su acatamiento por parte de los poderes públicos. Sólo la adjudicación de sus normas da cuenta de la subordinación de los poderes públicos a su imperio. Esta es la razón de la primacía constitucional. De esto, las cláusulas de supremacía son sólo una descripción, no su fundamento. Fundar la primacía de la constitución en su cláusula de supremacía es incurrir en un razonamiento circular: es afirmar que la constitución es suprema porque ella dice que lo es.

De lo segundo el rastro es más antiguo. Ya en 1831 el contencioso-administrativo estaba en la Constitución (artículo 113.3) ${ }^{14}$. Y la Constitución anterior se refería expresamente a él como jurisdicción especializada (artículo 116.III) ${ }^{15}$, como recurso (artículo 118.3) ${ }^{16}$ y como proceso (artículo 118.7) ${ }^{17}$. Salvo lo referido a la jurisdicción agroambiental (artículo 189.3), nada de esto está hoy. La redacción no dice nada, pero la norma lo dice todo. La regla constitucional es que las actuaciones administrativas son enjuiciables judicialmente. Aquí la herencia republicana lo define todo. (1) Si no lo fueran, este no sería un Estado de Derecho (artículo 1). (2) Para que no lo fuesen, la Constitución tendría que prohibirlo expresamente (porque hace a la mismidad del Estado de Derecho). Como no hay tal prohibición, su enjuiciamiento es válido. Y (3), como tampoco hay prohibición constitucional que pese sobre la causa de pedir, son enjuiciables las actuaciones en general de la administración (actos administrativos, hechos administrativos, vías de hecho, omisión de actos y prestaciones debidas), y no sólo su manifestación en la forma de actos (decisión formal). Aquí la competencia del poder judicial la define el silencio de la Constitución (ausencia de norma contraria) y el derecho a la tutela judicial efectiva (artículo 115.I de la Constitución): por sus fines, el proceso contencioso-administrativo no pretende el saneamiento per se del sistema jurídico, sino la tutela de los derechos del administrado (plena jurisdicción). Para esto, la anulación del acto administrativo dañoso es un remedio (control objetivo), pero no el único.

\footnotetext{
14 «Son atribuciones de la Corte Suprema de Justicia: (...). Conocer de las causas que resulten de los contratos o negociaciones del Poder Ejecutivo».

${ }^{15}$ «La facultad de juzgar en la vía ordinaria, contenciosa y contencioso-administrativa y la de hacer ejecutar lo juzgado corresponde a la Corte Suprema y a los tribunales y jueces respectivos, bajo el principio de unidad jurisdiccional».

16 «Son atribuciones de la Corte Suprema: (...). Resolver los recursos de nulidad y casación en la jurisdicción ordinaria y administrativa».

${ }^{17}$ «Son atribuciones de la Corte Suprema: (...). Resolver las causas contenciosas que resulten de los contratos, negociaciones y concesiones del Poder Ejecutivo y las demandas contencioso-administrativas a las que dieren lugar las resoluciones del mismo».
} 


\section{LEGITIMIDAD DEMOCRÁTICA DE LOS TRIBUNALES}

5. Que la justicia emane del pueblo (artículo 178.I) es un indicio de la independencia del poder judicial. Pero no es suficiente. Esta declaración es una reiteración del artículo 7. Ha estado siempre en la Constitución. Se trata del principio de base de la república. Acá la «soberanía emana del pueblo y su ejercicio reside en los poderes [públicos]» (artículo 8 de la Constitución de 1826), que lo reciben por delegación. Esto hace al delegante contralor del poder judicial. No controla a los tribunales: el derecho aplicable in casu sólo lo deciden ellos. Controla la justificación de sus decisiones.

6. La justificación de las decisiones judiciales es connatural al Estado de Derecho. Es la fuente de legitimidad democrática de los tribunales. Sólo en el Estado de Derecho se considera que una decisión no está suficientemente justificada por el solo hecho de haber sido dictada por una autoridad competente (determinismo metodológico). Aquí, a la estabilidad formal de las decisiones, debe agregársele la corrección racional de su justificación. Hay corrección racional cuando las decisiones son justificables por su universalidad, su coherencia y su consecuencia con los valores del sistema (MacCormick) ${ }^{18}$. La decisión judicial está obligada a demostrar que la razón está objetivada en el derecho. Si este es un gobierno sub lege, la decisión judicial debe justificar que su voz viene del derecho (bueno o malo), no de la arbitrariedad ${ }^{19}$. Esta es la vía que el sistema jurídico da a los tribunales para que se posicionen a la par de los poderes ejecutivo y legislativo, con la sola autoridad de sus decisiones.

7. La justificación significa control democrático por dos razones. (1) Porque es la precondición de toda segunda instancia y de toda vía recursiva. Aquí los afectados accionan fundándose en la justificación de la decisión objetada. Piden que un órgano autorizado para enjuiciar los actos de otro se pronuncie al respecto. Se trata del sistema de frenos y contrapesos aplicado intra organum y pro-

${ }^{18}$ Cf. MacCormick, Neil; Legal Reasoning and Legal Theory (1 $1^{\mathrm{a}}$ edición, Nueva York, Clarendon Press, 1978).

${ }^{19} \mathrm{El}$ siguiente es un ejemplo de un argumento (un dictum específicamente) que no viene del derecho: «(...) la emisión del Decreto Supremo 29836 tiene el principio de legalidad, por lo que los recurrentes no desconocen dicho principio, sino que, por tratarse de una coyuntura de la realidad social, solamente piden el tránsito de sus vehículos adquiridos en otros continentes o que se encuentran en tránsito al territorio nacional». «(...) cuando se observa colusión entre el derecho y la realidad social, debe aplicarse la justicia, que consiste en dar a cada cual lo que le corresponde, principio este que debe ser sustentado aplicando también el principio de favorabilidad, máxime si nos encontramos en un gobierno de los pobres, en un gobierno revolucionario» (CSD-LP, ResoluciónAC Sala Civil Segunda No. 8/09, 4 de febrero). 
movido como contenido de una pretensión procesal. Constituye el derecho a obtener una sentencia fundada, que nace de la tutela judicial efectiva y del debido proceso (artículo 115 de la Constitución, STC 937/2006-RAC, 25 de septiembre, párrafo III.3.1 ${ }^{20}$, y STC 1163/2006-RAC, 20 de noviembre, párrafo III. $2^{21}$ ). (2) Porque es la precondición para la creación judicial del derecho. Un precedente se afirma por la fuerza de su justificación. Y se lo cambia cuando la fuerza de otra justificación articula mejor en el sistema jurídico. Acá la justificación de las decisiones judiciales es una exigencia que viene del derecho a la igualdad ante la ley (artículos 8.II y 14.III) y de la garantía de seguridad jurídica (artículo 178.I).

8. El control democrático no es control social. El primero lo ejercen los individuos ex parte. El segundo lo ejerce la sociedad civil organizada (artículo 241.I). Y no es un control democrático. Es en sí mismo una contradicción. Se trata de ejercer la libertad de asociación a la fuerza. Todo intento de institucionalización de la sociedad civil la desnaturaliza como fuente de legitimidad democrática. Cuanta mayor institucionalidad se le brinde, menos sociedad civil es, y, por tanto, menos representación genuinamente civil. Al organizarla oficialmente se la asimila al aparato público y pasa a ser un poder político. Siempre que sea desde el Estado que se la organice, fortalecerla es debilitarla, y afirmarla, negarla ${ }^{22}$.

${ }^{20}$ «(...) cuando un juez omite la motivación de una resolución, no sólo suprime una parte estructural de la misma, sino también en los hechos toma una decisión de hecho no de derecho que vulnera de manera flagrante el debido proceso $(. .). » . \ll(\ldots)$ Esta exigencia de fundamentar las decisiones, se torna aún más relevante cuando el juez o tribunal debe resolver en apelación la impugnación de las resoluciones pronunciadas por las autoridades de primera instancia; (...) es imprescindible que dichas resoluciones sean suficientemente motivadas y expongan con claridad las razones y fundamentos legales que las sustentan y que permitan concluir, que la determinación sobre la existencia del agravio sufrido fue el resultado de una correcta y objetiva valoración de las pruebas (...)».

${ }^{21}$ «La motivación de los fallos judiciales está vinculada al derecho al debido proceso y a la tutela jurisdiccional eficaz, (...), y se manifiesta como el derecho que tienen las partes de conocer las razones en que se funda la decisión del órgano jurisdiccional, de tal manera que sea posible a través de su análisis, constatar si la misma está fundada en derecho o por el contrario es fruto de una decisión arbitraria $(\ldots) »$. «(...) se tendrá por satisfecha [la motivación] aún cuando estando redactadas de manera escueta, es decir breve pero concisa, permitan conocer de manera indubitable las razones que llevaron al juez a tomar la decisión en tal o cual sentido; de tal modo que las partes sepan los motivos en se fundó la resolución; y así, dada esa comprensión, puedan ser revisados los fundamentos a través de los medios impugnativos establecidos en el ordenamiento».

${ }^{22}$ Aquí tiene razón Sartori. «Para que el pueblo tenga poder (en serio), la condición irrenunciable es que el pueblo impida cualquier poder ilimitado. Esta condición debe ser mantenida intransigentemente, cualquiera que sea la maximización esperada para atribuir al pueblo más poder. En términos de feedback monitoring, esto quiere decir que el principio todo el poder al pueblo se debe transformar, poco a poco, en el principio todo el poder a ninguno» (SARTORI, Giovanni; ¿Qué es democracia?, $1^{\text {a }}$ edición, Madrid, Taurus, 2003, p. 80). 


\section{INDEPENDENCIA JUDICIAL}

9. La eficacia del Estado de Derecho depende de sus tribunales. La naturaleza autoritativa de sus decisiones les permite imponer el gobierno sub lege a los poderes públicos y a los civiles. A condición de que (1) sean independientes, especialmente del poder ejecutivo, (2) sus jueces sean independientes de los poderes públicos y de los órganos internos del gobierno judicial, (3) se rijan por el principio de unidad jurisdiccional, y (4) estén sometidos sólo al derecho positivo del sistema jurídico.

10. La independencia del poder judicial significa que tiene (1) un gobierno propio y (2) un presupuesto autónomo. De lo primero se encarga el Consejo de la Magistratura (artículo 195). Lo segundo es una garantía de su paridad constitucional con los poderes ejecutivo y legislativo (artículo 178.II.1). Si el gobierno judicial no estuviese a cargo de un órgano propio de carácter administrativo, habría que encargárselo al poder ejecutivo o habría que convertir a los tribunales en administradores. Las dos son opciones inaceptables. La primera porque hace al poder judicial dependiente del ejecutivo. La segunda porque desnaturaliza las funciones de los órganos de línea de la judicatura.

11. Los tribunales son independientes cuando su estatus jurídico los hace inmunes a las presiones del poder. El derecho anglo-americano lo consigue haciéndolos inamovibles en sus cargos. En el sistema inglés es una garantía que en tiempos modernos viene de la Ley de Establecimiento (1701), que comisionaba a los jueces quamdiu se bene gesserint (en tanto se comporten bien). El sistema americano la tomó para sí y la introdujo en su Constitución (artículo III.1) ${ }^{23}$. Los proyectos presentados a la Convención de Filadelfia (1787) por los estados de Virginia y de Nueva Jersey y por Hamilton ni siquiera innovaron el lenguaje. Y la moción de Dickinson de añadir «no obstante podrán ser removidos por el Ejecutivo por decisión del Senado y de la Cámara de Representantes», sólo tuvo el favor de su propio voto ${ }^{24}$, a pesar de inspirarse en el antecedente inglés ${ }^{25}$. Los pa-

$23 \ll(\ldots)$. Los jueces, tanto de la Corte Suprema como de los inferiores, continuarán en sus puestos mientras observen buena conducta y recibirán, en períodos fijos, una remuneración por sus servicios, que no será disminuida durante el tiempo de su cargo».

${ }^{24}$ Madison, James; Notes of Debates in the Federal Convention of 1787 reported by James Madison (1 ${ }^{a}$ edición, Nueva York, 1987), pp. 32, 120, 138, y 536-537.

${ }^{25}$ El párrafo completo decía: «Que una vez entren en vigor las limitaciones previamente citadas, las comisiones de jueces se realizarán quamdiu se bene gesserint, y se determinarán y fijarán sus salarios. Ello no obstante, podrán ser legalmente removidos por decisión de ambas Cámaras del Parlamento». 
dres fundadores de la Unión vieron con claridad la relación entre la eficacia del Estado de Derecho y el estatus jurídico de sus tribunales. «Esa adhesión uniforme e inflexible a los derechos de la Constitución y de los individuos, que comprendemos que es indispensable en los tribunales de justicia, manifiestamente no puede esperarse de jueces que estén en posesión de sus cargos en virtud de designaciones temporales. Los nombramientos periódicos, cualquiera que sea la forma como se regulen o la persona que los haga, resultarían fatales para esa imprescindible independencia» (Hamilton) ${ }^{26}$. También lo vio Bolívar: «Durarán los magistrados y jueces tanto cuanto duraren sus buenos servicios» (artículo 100 de la Constitución de 1826). En las primeras reformas constitucionales (1831) este texto fue suprimido.

En el sistema continental la independencia de los jueces significa (1) que las causales para su remoción son cerradas (numerus clausus), (2) que están sujetos a un régimen de incompatibilidades y (3) que siguen una carrera judicial.

Lo primero no está en la Constitución. Respecto de los jueces de los altos tribunales (Supremo, Agroambiental y Constitucional), hay causales de remoción en el artículo 183.II, y en los artículos 188 .III y 200 por remisión a aquél, y en el artículo 195.1. Los primeros disponen su cesación por sentencia ejecutoriada pronunciada en juicio de responsabilidades, y el artículo 195.1 por revocatoria popular de su mandato. Los jueces del Tribunal Constitucional quedan al margen de esta causal. (1) El Consejo de la Magistratura no tiene competencia para promover la revocatoria en su contra. (2) Están cubiertos por la exclusión general del artículo 240.I, que exceptúa la revocatoria popular de los cargos del poder judicial. Pero ninguno de estos artículos cierra las causales de remoción. El artículo 183.II permite a la Asamblea Legislativa crear nuevas causales; y el artículo 195.1 la obliga a hacerlo, dándole competencia para determinar las faltas administrativas «gravísimas» que justifiquen convocar al electorado en una revocatoria. Como causal de remoción, la revocatoria popular expone injustificadamente a los jueces a las presiones de la opinión pública (párrafo 13). Su adopción es consecuencia del simplismo de creer que, para que tengan legitimidad democrática, los jueces de los altos tribunales deben tener origen popular (párrafo 6). Respecto de los jueces de los tribunales superiores y de los de instancia, la Constitución los deja expuestos a lo que disponga la Asamblea Legislativa para su remoción (artículo 195.2). Que la Asamblea Legislativa cree nuevas causales de remoción hace vana su regulación constitucional. Lo mismo pasó en las reformas

${ }^{26}$ Hamilton, Alexander - Madison, James - JAY, John; The Federalist Papers (1 $1^{\mathrm{a}}$ edición, Nueva York, Buccaneer Books, 1993), p. 335. 
constitucionales de 1961 (artículo 126) ${ }^{27}$, y ya desde 1851 se arrastraba la misma debilidad, pero referida a las causales de suspensión (artículo 90) ${ }^{28}$. Para que las causales de remoción fuesen cerradas debía volverse al pasado. Ya en 1843 la Constitución decía: «Ningún empleado del ramo judicial podrá ser depuesto de su destino, sea temporal o perpetuo, sino por sentencia ejecutoriada; ni suspenso, sino por auto en que se declare haber lugar a la formación de causa» (artículo 75). Ya respecto de ésta la Constitución anterior conllevaba un retroceso, porque con su silencio encomendaba la regulación de las causales de suspensión a otro poder (artículo 116.VI) ${ }^{29}$. Pero, respecto de ambas, la Constitución vigente es la más atrasada. En las otras la causal de remoción cubría a todos los jueces, al margen de su grado. En ésta no cubre a ninguno. O por su silencio o porque lo encomienda expresamente, la remoción y suspensión de todos queda abierta a lo que disponga otro poder.

Lo segundo está en los artículos 236 y 239. El primero regla las prohibiciones para el ejercicio de la función pública y el segundo las causales de incompatibilidad. Ambos son aplicables a los jueces de los altos tribunales por remisión de los artículos 182.VII, 188.II y 201, y a todos los demás jueces por aplicación del artículo 233 (juzgar es una función pública). Acá el poder legislativo no tiene competencia. Los artículos 236 y 239 son cláusulas cerradas: todo lo que el sistema jurídico podía decir sobre el tema, se agotó en su regulación constitucional. Y lo tercero está en el artículo 178.II.1, que hace a los jueces funcionarios públicos de carrera.

12. Hay unidad jurisdiccional cuando la justicia que emana del pueblo (artículo 178.I) sólo la ejerce el órgano por él delegado. Dice de su monopolio por parte del Estado y de su encargo al poder judicial. Arraiga en la división de poderes. Viene de la prohibición de delegación de las competencias públicas (artículo 12.III). Está en la declaración de unicidad de la función judicial (artículo 179.I) y en la prohibición de tribunales de excepción (artículo 180.III, como derecho, artículo 120.I).

El poder judicial está formado por una pluralidad de órganos independientes entre sí (jueces y tribunales). Forman una unidad si sus decisiones son revisables, directa o indirectamente, por un único órgano supremo. En los sistemas que vienen del common law, la unidad la dan las cortes supremas. Aunque

27 «(...), ningún magistrado o juez podrá ser destituido sino por sentencia ejecutoriada, a no ser en los casos determinados por ley».

28 «Ningún magistrado o juez puede ser privado de su destino, sino por sentencia ejecutoriada, ni suspenso, sino conforme a las leyes».

29 «(...). No podrán ser destituidos de sus funciones, sino previa sentencia ejecutoriada». 
en los niveles inferiores la jurisdicción es especializada, la competencia de las cortes supremas no queda cercenada. El único alto tribunal son ellas. En los sistemas que evolucionaron de la Revolución Francesa, la unidad la dan los tribunales constitucionales. Acá no hay diferencia con los sistemas del common law: mientras que en la tradición romano-germánica la defensa de la constitución se encarga a un tribunal especializado, el mundo anglo-americano la confía a sus cortes supremas. En ambos casos la unidad de la jurisdicción viene de la unidad de la norma fundacional del sistema jurídico. Sólo puede venir de allí. Esa norma es la constitución. Y la unidad jurisdiccional es la representación funcional de su defensa. No hay decisión judicial que no pueda ser enjuiciada por violaciones constitucionales: todas están sujetas al imperio de la constitución. Y, por tanto, lo están a la competencia de su custodio: las decisiones de la jurisdicción ordinaria y de sus jurisdicciones especializadas, de la jurisdicción militar (artículo 180.III), de la jurisdicción agroambiental y de la jurisdicción indígena originario campesina ${ }^{30}$, son todas enjuiciables por el Tribunal Constitucional Plurinacional.

${ }^{30} « \mathrm{El}$ derecho indígena originario campesino es una costumbre secundum legem. Existe como derecho porque la Constitución remite a él (artículos 30.II.14, 190.I y 191.I). Esto lo subordina a la Constitución y condiciona su validez a los términos de su remisión. Según estos términos, para ser válido debe (1) respetar los derechos y garantías constitucionales (artículo 190.II) y (2) debe limitarse a regular las materias de competencia de los subsistemas indígena originario campesinos. Hasta aquí llega el derecho de las naciones o pueblos indígena originario campesinos al ejercicio de su sistema jurídico de acuerdo a su cosmovisión (artículo 30.II.14). Este es su ámbito de validez material. Fuera de él se vuelve conducta ilícita». (...). «Esto significa que (1) las decisiones de la jurisdicción indígena originario campesina son controvertibles en la jurisdicción constitucional. El límite de la obligación de «toda autoridad pública o persona [de acatar] las decisiones de [esta] jurisdicción» (artículo 192.I) son los derechos garantizados por la Constitución. De violárselos, la jurisdicción constitucional está autorizada a tutelarlos. (2) El ejercicio de la jurisdicción indígena originario campesina puede ser contestado por las jurisdicciones ordinaria y agroambiental. Acá es el Tribunal Constitucional Plurinacional el que decide el asunto (artículo 202.11). Y, (3) que si el asunto controvertido es la existencia misma de una práctica consuetudinaria (precondición para el ejercicio de la jurisdicción), la misma deberá probarse. Por su propia naturaleza, la regla iura novit curia no es aplicable a la costumbre. Al estar formada por hechos, las reglas consuetudinarias son objeto de prueba. Esto garantiza que lo aplicado sea una costumbre válida como derecho. De otro modo no puede diferenciarse su existencia del alegato de la parte que la invoca. Así es en el derecho internacional. Acá la carencia de órganos productores centralizados hace que la costumbre tenga el protagonismo que otrora lo tuvo en el derecho interno. En el asunto de la Delimitación de la frontera marítima en la región del Golfo de Maine (Canadá/Estados Unidos) (1984), la Corte Internacional de Justicia dijo: «[en] las reglas consuetudinarias la existencia de la opinio iuris de los Estados se prueba por vía de inducción, tomando como punto de partida el análisis de una práctica suficientemente amplia y convincente, y no por vía de deducción a partir de ideas concebidas a priori» ${ }^{30}$. También los de- 
No hay antinomia entre la unidad jurisdiccional y (1) el arbitraje, (2) la función jurisdiccional de la administración (procedimientos y recursos administrativos) y (3) las decisiones de naturaleza judicial tomadas por órganos políticos (vg. enjuiciamiento a los jueces de los altos tribunales, artículo 160.6 de la Constitución). Respecto a lo primero, porque la competencia de los árbitros no emana del pueblo. Actúan por mandato de la voluntad de las partes, que en ejercicio de su libertad general de actuación (artículo 14.IV de la Constitución) disponen (por derivación, artículo 56.I de la Constitución) de sus derechos, encargando la resolución de sus controversias a un tercero. Respecto a lo segundo, porque las decisiones tomadas en sede administrativa son enjuiciables por los tribunales. El administrado puede consentirlas o enjuiciarlas. Si se decide por lo primero, su consentimiento es en naturaleza jurídica un acto de disposición sobre sus derechos. Si se decide por lo segundo, la decisión que causa estado la toman los tribunales. Respecto a lo tercero, porque cuando dictan decisiones de naturaleza judicial, los órganos políticos actúan, funcionalmente, como órganos judiciales. Y respecto de los tres en común, porque todo acto de aplicación del derecho está sujeto a las garantías constitucionales para el ejercicio de la jurisdicción y, por tanto, a la competencia del Tribunal Constitucional para su enjuiciamiento. Si no fuera así, estarían fuera del sistema jurídico.

13. El sometimiento de los tribunales al derecho positivo del sistema jurídico significa (1) que sus decisiones sólo están justificadas si es que sus argumentos son jurídicos y (2) que están obligados por sus precedentes. Acá son ellos mismos los garantes de su independencia.

Lo primero hace de los jueces funcionarios independientes (i.e. vinculados sólo al derecho positivo del sistema jurídico), aún cuando su fuente de origen sea electiva. Que un órgano sea electo por voto popular no significa que tenga poder de decisión política. La decisión política se justifica en los fines que persigue. La opción por una entre varias alternativas se apoya en los efectos previsibles de la decisión, con relación al fin que le sirve de fundamento. «La moral política se ocupa principalmente de crear las condiciones que propicien el desarrollo de gustos y temperamentos deseables $»^{31}$. Por definición, esto no ocurre con la judicatura. Aquí las decisiones sólo pueden estar justificadas si es que sus argumentos son de derecho positivo (párrafo 6). En términos de la eficacia del sistema, sin

rechos estatales exigen la prueba de la costumbre. Dice el Código Civil de España: «La costumbre sólo regirá en defecto de ley aplicable, siempre que no sea contraria a la moral o al orden público y que resulte probada» (artículo 1.3)» (ANDALUZ, Horacio; Aplicación judicial de la constitución, $1^{a}$ edición, Santa Cruz, El País/Iuris Tantum/UPSA, 2010, pp. 63 y 64).

${ }^{31}$ RAz, Joseph; On the Autonomy of Legal Reasoning, en Ethics in the Public Domain (1 ${ }^{\text {a }}$ edición, Oxford, Clarendon Press, 1994), p. 360. 
embargo, la elección por voto popular de los jueces de los altos tribunales (artículos 182.I, 188.I y 198) puede devenir en contra del diseño institucional del poder judicial. Si del voto depende el nombramiento, granjearse la opinión favorable del elector es asunto decisivo. Con esto, la independencia judicial puede ceder ante la opinión pública, haciendo del sometimiento al derecho el sometimiento a las corrientes de opinión preponderantes.

Lo segundo abona a la confianza en el poder judicial. La precondición para que los tribunales sean verdaderamente inmunes a las presiones de poder es que existan con la dignidad de un auténtico poder del Estado ante el ciudadano. Esto lo construye el carácter vinculante de sus decisiones. (1) La unidad de la jurisprudencia beneficia al ciudadano. Redunda en certeza y previsibilidad respecto de las decisiones de los poderes públicos, incluyendo las judiciales: «aún cuando los predecesores hubiesen sido malos, ignorantes, tontos o parcializados, la certeza de que sus sucesores seguirán sus precedentes da la base para que se pueda prever las acciones de los tribunales» ${ }^{32}$. (2) Las garantías del ciudadano penden del supuesto de que el poder frene al poder. El derecho es en naturaleza un sistema de seguridad. El carácter vinculante de los precedentes trabaja a favor de esto. El decisor que basa sus acciones en normas anticipa el sentido de sus futuras decisiones. Esto satisface un principio general de consistencia, que hace a la esencia misma de la seguridad jurídica. Y (3) el tema envuelve la unidad del sistema jurídico. Al conllevar la realización de sus premisas conceptuales mismas, la unidad redunda en la eficacia del sistema. Y la premisa por excelencia de cualquier sistema normativo, incluso de uno totalitario, es que la sola existencia de normas de aplicación cierta ya supone limitar la arbitrariedad.

El carácter vinculante de los precedentes lo da la Constitución. (1) La Constitución es una norma dotada de contenido, y (2) parte de ese contenido es la igualdad de las personas ante la ley (artículos 8.II y 14.III) y la garantía de seguridad jurídica (artículo 178.I). (3) Esto significa que ante todos los hechos «A» el derecho debe ser «B» («A» supone la identidad fáctica del supuesto y sus circunstancias y «B» las mismas consecuencias jurídicas). (4) En consecuencia, de la propia Constitución nace el respeto a los precedentes, en sus respectivas materias, del Tribunal Constitucional Plurinacional, del Tribunal Supremo de Justicia y del Tribunal Agroambiental. (5) A contrario, si ante los hechos «A» el derecho no fuera $« \mathrm{~B} »$, sino indistintamente $« \mathrm{C} »,\langle\mathrm{D} » \mathrm{O} \ll \mathrm{E} »$, entonces no habría igualdad ante la ley ni seguridad jurídica.

${ }^{32}$ LLeWelLyN, Karl; The Bramble Bush (reimpresión, Nueva York, Oceana/Oxford University Press, 1961), p. 65. 
La obligatoriedad de los precedentes tiene el mismo fundamento en los sistemas del common law y en los que son herederos de la tradición continental. Si acá su carácter vinculante no es respetado, no es por razones de derecho positivo. Lo es por una suma de equívocos, y el error no engendra derecho. (1) La violencia de la Revolución Francesa llevó la división de poderes al equívoco de asumir que sólo el cuerpo legislativo creaba derecho. Hasta tiempos prerrevolucionarios, los tribunales continentales actuaban de manera similar a los ingleses. Iban desarrollando un cuerpo de normas de creación judicial y su propia doctrina del precedente ${ }^{33}$. La Revolución los interrumpió. Reclamaba el monopolio en la producción jurídica para consolidar sus reformas por medio del derecho. Quería asegurarse el acompañamiento de los tribunales al proceso revolucionario juridizado por la Asamblea Nacional. La dramática separación conceptual entre creación y aplicación del derecho respondía a la necesidad ideológica de legitimación del poder público. La imagen de una autoridad creando derecho, pero no derivando su poder de la elección del pueblo soberano, rompía con el simplismo que se asumió la división de poderes. (2) La ideología de la codificación, como producto del naturalismo racionalista de los siglos XVII y XVIII, creyó haber encontrado unas leyes universales llamadas a regir el comportamiento humano. Esto degeneró en la exageración de la importancia de los códigos, y del derecho de fuente legislativa en general, como si fueran los depositarios de todo el derecho. Y (3), como consecuencia de (1) y (2), el predominio de la Escuela de la Exégesis dio el soporte filosófico para reducir a los tribunales a la pura aplicación mecánica del derecho. No podían participar en el proceso de creación normativa porque eso correspondía a las legislaturas (aserto 1). Y no tenían motivos para hacerlo. El alto grado de perfección de los códigos excluía la necesidad de su interpretación (aserto 2). Un discurso que sonaba coherente, pero que en verdad contraría la coherencia del sistema, arrebató a los tribunales su poder normativo.

\section{DERECHO ORDINARIO}

14. Hasta aquí la Constitución. Pero el derecho ordinario está fuera de ella. Objetivamente, ha legislado para un poder judicial subordinado.

Ya en mayo de 2007 el poder ejecutivo dirigió contra el judicial el que fue, hasta ese momento, su embate más fuerte, por sus efectos. A raíz de la decisión del Tribunal Constitucional de cesar en sus funciones a cuatro ministros de la

${ }^{33}$ Cf. Merryman, John Henry; La tradición jurídica romano-canónica ( $8^{a}$ reimpresión, México D.F., Fondo de Cultura Económica, 2003), pp. 47-59, 72-80. 
Corte Suprema, nombrados interinamente por el Presidente de la República ${ }^{34}$, el ejecutivo inició un juicio de responsabilidades contra cuatro de los cinco magistrados del Tribunal ${ }^{35}$. El juicio terminó siendo archivado por la Cámara de Senadores. Pero, en tanto acción de hostigamiento, por igual concluyó en el alejamiento de los cuatro magistrados. Esto, sumado a la no designación por el Congreso de los nuevos magistrados, mantuvo al Tribunal en estado de inoperancia hasta el 2010. En términos de eficacia, durante ese tiempo Bolivia no tuvo Constitución. Luego, el 17 de febrero de 2010, el poder ejecutivo cubrió con interinos los cargos vacantes del Tribunal Constitucional, la Corte Suprema y el Consejo de la Judicatura (Decreto Supremo 432). El resultado: si el efecto propio de un interinato es la libertad de nombramiento y remoción del interno, el poder bajo autoridad interina depende del poder habilitado para disponer de él. Con esto, la independencia del poder judicial queda sujeta a la templanza del ejecutivo para no subordinarlo efectivamente. Todo lo contrario al sistema de frenos y contrapesos constitutivo de un gobierno de poderes limitados.

Como habilitación normativa, el poder ejecutivo se apoyaba en la Ley de necesidad de transición a los nuevos entes del Órgano Judicial y Ministerio Público (Ley 3), dictada días antes (13 de febrero de 2010). Ya aquí el poder legislativo había dispuesto (1) que el ejecutivo cubriría las vacancias dichas (artículo 3.2), (2) declarar transitorios de los cargos de los altos tribunales (Constitucional, Supremo y Agrario) y del Consejo de la Judicatura (artículo 3.1 original), lo que prontamente fue ampliado a todo el poder judicial, extendiéndose la declaratoria de transitoriedad a las Cortes Superiores de Distrito y los juzgados (artículo 3.1 modificado por Ley 40), y (3) prorrogar la suplencia del Fiscal General de la República (artículo 5.1). La Constitución en vigor calla en lo que respecta a los cargos interinos. No obstante el argumento del tránsito hacia el nuevo orden constitucional, lo cierto es que el poder legislativo estaba normando inconstitucionalmente. (1) En cuanto a la prórroga del Fiscal General, lo que le correspondía era designar al titular, que es competencia reservada al propio legislativo (artículo 161.8). (2) En cuanto a las vacancias de los altos tribunales y del Consejo de la Judicatura lo que correspondía era poner en movimiento las propias disposiciones transitorias de la Constitución, con docentes a la designación por voto popular en sus titulares (dispsiciones transitorias segunda y cuarta). La Constitución anterior permitía

${ }^{34}$ Cf. STC 0018/2007-RDI (9 de mayo).

${ }^{35}$ El Presidente de la República justificó el inicio del juicio diciendo: «algunas instituciones del Estado están por demás» (http://www.padep.org.bo/www/index.php?pg=actualidad/rnoticias/Anteriores/160507/). 
el nombramiento de interinos en caso de renuncia o muerte, correspondiendo tal competencia al poder ejecutivo (artículo 96.16). Esta constitución calla al respecto. El significado jurídico de su silencio es simple: si la Constitución no está habilitando con competencia a ningún órgano para desiguar interinos, entonces ningún órgano puede designarlos. De lo contrario, ya no sería un gobierno de poderes limitados, sino uno en el que arrogarse competencias que no nacen de la Constitución sería válido. Si esto fuera así, la Constitución saldría sobrando. Ni siquiera en un supuesto de estado de necesidad podría el poder ejecutivo designar interinos. Si los titulares de dichos cargos deben ser electos por voto popular de entre los preseleccionados por la Asamblea Legislativa (artículos 158.I.5, 182.I, 188.I, 194 y 198), sus interinos debieran ser nombrados por el órgano que ostenta la representación democrática más cercana a la del elector que elige a los titulares, y como tal elector es el pueblo soberano, tal órgano debiera ser el legislativo. (3) En cuanto a la declaratoria de transitoriedad de los cargos, respecto a los funcionarios afectados, la Ley viola la regla de irretroactividad asumida por la Constitución (artículo 123), que les garantiza la permanencia en su puesto hasta la finalización del período para el que fueron designados, aunque lo hubiesen sido conforme a la Constitución anterior. Y, respecto a lo que entraña como acto de desconocimineto del estatus jurídico que hace a los tribunales inmunes a las presiones del poder, por el solo dictado de la Ley, la declaratoria de transitoriedad supone desde ya violar su independencia (artículos 12.I y 178.I), aún cuando no hubiese una voluntad efectiva de dominación.

15. A esto deben sumarse otras dos disposiciones, que también son «indicio de situaciones críticas para la Constitución» ${ }^{36}$. (1) El Decreto Supremo 138 (20 de mayo de 2009), que hizo a la ciudad de La Paz sede exclusiva para el juzgamiento de los delitos de terrorismo, sedición y alzamientos armados contra la seguridad y soberanía del Estado (artículo 2), a despecho, en lo formal, de la reserva de ley para la regulación de los derechos (artículo 109.II de la Constitución) y, en lo material, del derecho al juez natural (artículos 115.II, 117.I y 120.I de la Constitución). (2) La Ley Marco de Autonomías y Descentralización (Ley 31, de 19 de julio de 2010), que autoriza la suspensión de los titulares de los órganos ejecutivos y legislativos autónomos (departamentales y municipales) con la sola acusación formal en su contra (artículo 144), dictada por el fiscal asignado al caso.

${ }^{36}$ Tomo, por su elocuencia, el párrafo de apertura del El Tribunal del Reich como Guardián de la Constitución (1929): «La demanda de un protector, de un defensor de la constitución es, en la mayoría de los casos, indicio de situaciones críticas para la constitución» (SchmitT Carl; La defensa de la Constitución, $2^{\text {a }}$ edición, Madrid, Tecnos, 1998, p. 27). 
Y a esto, a su vez, debe agregársele el ropaje de juridicidad con que el Tribunal Constitucional ha dado cobija a decisiones que, objetivamente, limitan el ejercicio de los derechos. Tal es el caso del juez preconstituido por ley.

\section{EL JUEZ PRECONSTITUIDO POR LEY EN LA JURISPRUDENCIA}

16. El Tribunal Constitucional ha producido un nuevo precedente sobre el juez preconstituido por ley ${ }^{37}$ (STC 99/2010-RAC, 10 de mayo, párrafos III.4 a III.7, luego aplicado en la STC 966/2010-RAC, 17 de agosto, párrafo III.3). Dice que a esta garantía le corresponde un «resguardo reforzado». Esto es correcto. Pero el mismo se desdice: su interpretación importa, al cabo, negar que esta sea una garantía de fuente constitucional, porque sólo no siéndola se justifica que no la tutele, y como el Tribunal de hecho le ha esquivado la prestación de tutela, ha terminado diciendo, a pesar suyo, que no nace de la Constitución.

El juez preconstituido por ley (juez natural competente) es parte del contenido de la garantía general del debido proceso (artículos 115.II, 117.I y 120.I de la Constitución). Como tal, su regulación está reservada al poder legislativo (artículo 109.II). Jurídicamente, significa que (1) los juzgados y tribunales sólo pueden ser creados por ley, (2) que, además, su composición personal sólo pueden ser determinada por una ley que establezca el procedimiento para la designación de sus miembros, (3) que sólo una ley puede investirlos de jurisdicción y competencia (con anterioridad al hecho que motiva su actuación), y (4) que, en definitiva, quedan prohibidos los tribunales de excepción (artículos 120.I y 180.III). Por tanto, la violación de cualquiera de estos supuestos habilitaría al Tribunal para tutelar al afectado. Pero esto es lo que la nueva línea jurisprudencial acaba por impedir.

17. Reconstruido, así discurre el argumento del Tribunal: (1) La violación de cualquiera de los supuestos anteriores significa una actuación sin competencia.

\footnotetext{
${ }^{37}$ Para el Tribunal Constitucional el juez natural incluye las garantías de competencia, independencia e imparcialidad (STC 491/2003-RAC, 15 de abril), de acuerdo a los artículos 8 de la Convención Americana de Derechos Humanos y 14 del Pacto Internacional de Derechos Civiles y Políticos, que son parte del bloque de normas constitucionales. Acá sólo me refiero al juez natural competente. Uso la denominación de juez preconstituido por ley para evitar que mis críticas a los nuevos precedentes constitucionales sobre la competencia del juez natural sean equívocamente extendidas a los elementos de imparcialidad e independencia, a causa del error, entendible por compartir el mismo sustantivo, de confundir el género (juez natural) con la especie (competencia). Los textos entrecomillados corresponden a la STC 99/2010-RAC, 10 de mayo, párrafos III.4 a III.7.
} 
Cierto. (2) Los actos ultra vires (sin competencia) son materia «específica» del recurso directo de nulidad. Falso: no cuando violan un derecho fundamental. (3) Por tanto, este es el «mecanismo idóneo, inmediato, eficaz y específico para [la] protección» del juez preconstituido por ley. Falso. Y (4) si la vía es el recurso directo de nulidad, entonces, por exclusión, la acción de amparo constitucional no tutela esta garantía. Falso.

Se trata de una falacia de accidente (tratar lo accidental como esencial): considera que aquellas propiedades que accidentalmente se encuentran en una categoría conceptual, definen su esencia (como inferir de Bach y Pachelbel, como compositores barrocos alemanes, que los compositores barrocos fueron siempre alemanes).

Aquí está el error. Se confunde la razón de la pretensión procesal de la acción de amparo (causa de pedir) con su objeto (el efecto que produce el procedimiento). Como en la acción de amparo contra un acto de juez incompetente y en el recurso directo de nulidad el objeto de la pretensión es el mismo (genéricamente, la declaratoria de incompetencia), el Tribunal asume que la razón de la pretensión de los dos procedimientos es también la misma. Pasa por alto que la coincidencia en el objeto es aquí un accidente. Lo que hace que la acción de amparo y el recurso directo de nulidad no sean lo mismo es, precisamente, la razón de sus respectivas pretensiones procesales. Esa es la esencia de cada cual.

En el recurso directo de nulidad la razón de la pretensión es la integridad objetiva de la distribución constitucional de competencias. La causa de la impugnación es la actuación ultra vires. Acá, el solo hecho de la falta de competencia asegura una decisión estimativa de la pretensión. La expresión de agravios que se exige al recurrente es tan solo un presupuesto procesal para la admisión del recurso. A contrario: aún cuando no se viole un derecho constitucional, habrá decisión estimativa siempre que haya actuación sin competencia.

En la acción de amparo, en cambio, la razón de la pretensión es la tutela de los derechos constitucionales. Es una acción de defensa. Acá lo que importa no es si los derechos fueron lesionados por un acto sin competencia (ultra vires), sino, desnudamente, el hecho de que hayan sido lesionados. La expresión de agravios es aquí a la vez un presupuesto procesal y un presupuesto sustantivo para la obtención de una decisión estimativa de la pretensión. Sin daño a un derecho constitucional, no hay decisión estimativa. Ergo, si el juez preconstituido por ley es una garantía constitucional, entonces cualquier lesión a esta garantía debe remediarse por la acción de amparo, sea que haya o no sido causada por una actuación sin competencia. Negar esto ya es bastante error: 
equivale a decir que el juez natural competente no es una garantía constitucional, porque lo que no es defendible por la acción de amparo, no es un derecho constitucional.

18. Pero no es el único. El Tribunal también ha confundido dos presupuestos procesales distintivos de ambos procedimientos, equiparando el del recurso directo de nulidad con el de la acción de amparo, sin reparar en que el recurso directo de nulidad es, por definición, directo.

Según el Tribunal, para la procedencia del recurso directo de nulidad «se deben agotar previamente los mecanismos internos efectivos para la restitución de la garantía de competencia». Esto se llama subsidiaridad, y es un presupuesto para la procedencia de la acción de amparo. El recurso directo de nulidad, en cambio, desde que es tal (directo), no supone el agotamiento de ninguna vía procesal previa, habida cuenta que sólo procede ante la falta de previsión de vías por parte del sistema jurídico. De haber una vía que remedie la cuestión de competencia, ésta excluye la procedencia del recurso. Lo que, llevado al juez preconstituido por ley, significaría que la jurisdicción constitucional jamás podría tutelarlo, porque de hecho todas las leyes de procedimiento consideran mecanismos excluyentes del recurso directo de nulidad (i.e. excepción de incompetencia, inhibitoria, declinatoria).

Si a consecuencia de la falacia de accidente resulta que el juez preconstituido por ley no es tutelable en vía de amparo, a consecuencia de desplazarlo hacia el recurso directo de nulidad, resulta que ni siquiera sería de origen constitucional, porque sólo lo que no nace de la Constitución no puede ser conocido por el Tribunal Constitucional, de donde el «resguardo reforzado» enunciado por el Tribunal, termina desguarneciendo a una garantía fundamental de tutela constitucional.

Title:

ON THE CONSTITUTIONAL POSSITION OF THE JUDICIARY POWER IN BOLIVIA

\section{Summaty:}

I. Judiciary and separation of powers. II. Democratic legitimacy of the courts. III. Judicial independence. IV. Ordinary Law.V. The judge preconstituted by law in case law.

\section{Resumen:}

En el Estado de Derecho, el poder judicial se posiciona a la par de los poderes legislativo y ejecutivo. Esto lo consigue a través de su inde- 
pendencia. Este artículo explica eso desde el punto de vista doctrinal y lo aplica al análisis de la regulación en la materia en la Constitución de Bolivia de 2009.

\begin{abstract}
:
In the Rule of Law the judiciary power is positioned on the same level than the legislative and executive powers. This is so because of its independence. This article explains that from the doctrinal point of view while analyzing the regulation of the 2009 Bolivian Constitution on the subject.
\end{abstract}

\title{
Palabras Clave:
}

Estado de Derecho, poder judicial, independencia judicial, precedente.

\section{Key Words:}

Rule of Law, judiciary power, independence of the judiciary, precedent. 